Diabetologia 9, 185-190(1973)

(C) by Springer-Verlag 1973

\title{
Immune Reactions to Fractions of Crystalline Insulin
}

\section{Significance of Lymphocytic Infiltrates in the Endocrine and Exocrine Pancreas of Mice}

\author{
G. Freytag, F.K. Jansen and G. Klöppel \\ Institute of Pathology, University of Hamburg and Diabetes Research Institute at the University of Düsseldorf, \\ Germany
}

Received: September 7, 1972, accepted: February 16, 1973

\begin{abstract}
Summary. Mice immunized with once crystallized or chromatographed insulin at various doses throughout a period of three months, in order to investigate "tolerance induction" to different insulin preparations, unexpectedly revealed lymphocytic infiltrates in the endocrine and exocrine pancreas. Peri-insulitis, periductulitis and sometimes interstitial pancreatitis were observed both in animals injected with chromatographed insulin or once crystallized insulin, which can be fractionated into true Sanger insulin, a number of insulin compounds including proinsulin, and many undefined proteins of higher molecular weight. While the occurrence of periductulitis was not dependent on dosage, peri-insulitis was only found
\end{abstract}

with certain dose ranges in both groups. Injections of once crystallized insulin evoked peri-insular infiltrates at a low dosage, injections of chromatographed insulin at a high dosage. The possibility is discussed as to whether or not the peri-insular and peri-ductular infiltrates reflect a cellular immune response induced by fractions of crystalline insulin, which may differ from true Sanger insulin.

Key words: Histological alterations, exocrine pancreas, endocrine pancreas, insulitis, periductulitis, tolerance to insulin, insulin antibodies, cellular immune reaction, crystalline insulin, chromatographed insulin, monocomponent insulin, fractions of insulin.
Insulitis (von Meyenburg, 1940) is a rare but specific finding in diabetes mellitus. With few exceptions (LeCompte and Legg, 1972) this lymphocytic infiltration of the pancreatic islets is found in infantile and juvenile diabetios with a rapid course of the disease (LeCompte, 1958; Gepts, 1965; Steiner, 1958). Under experimental conditions lymphocytic insulitis could be observed in cattle (Renold et al., 1964), rabbits (Toreson et al., 1964) and sheep (Renold et al., 1969), when immunized with homologous and heterologous insulin. An acute type of insulitis with polymorphcellular and particularly eosinophil cells is found in rats (Lacy and Wright, 1965) and mice (Logothetopoulos and Bell, 1966; Freytag and Klöppel, 1969) injected with anti-insulin serum. While insulitis in passive immunization may be regarded as a local arthus phenomenon, i.e. an immune response of the immediate type, insulitis in active immunization is thought to be a cellular immune response to insulin, presumably with autoimmune character. When it was detected that crystalline insulin is heterogeneous and composed of true Sanger insulin (i.e. corresponding to Sanger's formula), certain derivatives with approximately the same molecular weight: desamidoinsulin, arginine insulin etc., proinsulin and its degradation products, a covalently connected dimer of insulin and many other uncharacterized proteins (Steiner et al., 1968; Schlichtkrull, 1969) the question arose, which fraction of the

Part of this work has been presented at the $56 \mathrm{th}$ Meeting of the German Association of Pathology, Graz, 1972.

* Supported by the Deutsche Forschungsgemeinschaft, Bad Godesberg and SFB 34, Hamburg, Germany. insulin preparation accounts for the specific character of the immune response.

This study was intended to compare the induction of high dose tolerance in mice immunized with once crystallized and chromatographed insulin (Jansen, 1971 , a, b). Unexpectedly, these animals revealed pancreatic changes which will be presented in this first paper. G. Freytag and G. Kloppel carried out the histological investigations, F.K. Jansen the immunological part.

\section{Materials and Methods}

\section{Animats}

Female NMRI mice with an average weight of $30 \mathrm{~g}$ were used in this experiment. They had free access to Altromin standard food and drinking water.

\section{Insulin Preparations}

The two insulin preparations used for immunization were kindly supplied by Dr. Schlichtkrull, Novo, Copenhagen: (1) once crystallized porcine insulin and (2) monocomponent porcine insulin, purified by chromatography. As shown by disc electrophoresis (Schlichtkrull, 1969), once crystallized insulin can be separated into several fractions, while monocomponent insulin cannot be further fractionized.

\section{Immunization Procedures}

13 sub-groups of ten mice each were immunized three times a week throughout a period of 12 weeks with different doses of both insulin preparations. The single dosage ranged from $1 \mathrm{ng}, 10 \mathrm{ng}, 100 \mathrm{ng}, 1 \mu \mathrm{g}, 10 \mu \mathrm{g}$ to $100 \mu \mathrm{g}$. The single insulin doses were dissolved in some drops of ammonia solution; thereafter $0.5 \mathrm{ml} 0.04 \mathrm{M}$ phosphate buffer $\mathrm{pH} 7.8$, containing $1 \%$ isologous serum, was added. 
The isologous serum was necessary to avoid the adsorption of insulin on the inner surface of the tubes, in which the dilutions were stored at $-25^{\circ} \mathrm{C}$, until required. These insulin preparations were injected intraperitoneally without any adjuvant. A considerable number of mice that had received the high doses of insulin died in hypoglycemia, although $2 \mathrm{ml}$ of $20 \%$ glucose was regularly given $1 \mathrm{~h}$ after injection. Particularly, many animals receiving high doses of once crystallized insulin died during immunization; consequently we had to examine this group as early as two months. One group of mice served as controls. They received buffer only throughout the period of 12 weeks. 13 days after the last administration of insulin without adjuvant, all animals, inoluding the controls, were subcutaneously injected with $0.5 \mathrm{ml}$ phosphate buffer containing $100 \mu g$ crystalline insulin, emulsified in $0.2 \mathrm{ml}$ Freund's adjuvant ( $50 \%$ complete Freund's adjuvant, 50\% incomplete) (Difco Lab., USA). This test immunization was given in order to determine whether tolerance to insulin existed after maximal stimulation of the antibody production. 5 months after the test immunization half of the animals were sacrificed. This long period of 5 months was chosen to verify tolerance induetion to insulin by controlling the insulin antibody contents. Throe weeks following a second test immunization, the other half of the mice was killed.

Insulin Antibody and Blood Glucose Determination

Blood glucose samples of untreated and treated mice were collected before sacrifice in order to estimate the antibody titre. The blood glucose level was checked twice during the study. Methodological details for the determination of antibody titer and blood glucose are given in a following paper (see part two).

\section{Histological Techniques}

The pancreas was removed immediately after death and fixed in Bouin's solution. Portions of heart, lung, liver, kidney, spleen and lymph nodes were fixed in $10 \%$ formalin solution. Sections were cut at different levels from the paraffin embedded blocks of the pancreas and other organs, and stained with haemalum-eosin, periodic acid Schiff (PAS), Giemsa or Gomori's aldehyde-fuchsin. The histopathological examinations were performed in a blind study only.

\section{Results}

Insulin Antibody Titre and Blood Glucose Levels: The data are given in the following papers.

\section{Histological Changes}

Controls: Seven out of eight controls showed no histopathological changes in the pancreas. A slight periductulitis and a focal interstitial pancreatitis were found in one animal. Sometimes interstitial infiltrates were observed in lung and liver.

\section{Animals Immunized with Once Crystallized or Chromatographed Insulin}

In 28 out of 87 animals of both groups a periductular infiltration (periductulitis) of the pancreas (see Fig. 1) was noted, which was sometimes accompanied by an interstitial pancreatitis. A diagnosis of periductulitis was accepted when the infiltrate consisted of more than 15 cells in serial section. As a rule, the infiltrate did not involve all pancreatic ducts. Ducts surrounded by inflammatory cells seemed to be dilated, but were otherwise intact. The infiltrate consisted of mononucleated cells which can be classified as lymphocytes and monocytic cells (immunoblasts?).

In 14 out of 87 animals, round-cell infiltrates were observed adjacent to an islet (peri-insulitis) (see Figs. 2

Table 1. Distribution and frequency of periductulitis in mice repeatedly injected with once crystallized or chromatographed insulin without adjwant at various dosages. Before death, a test immunization (cryst. insulin plus adjuvant) was given once or twice to prove induction of tolerance.
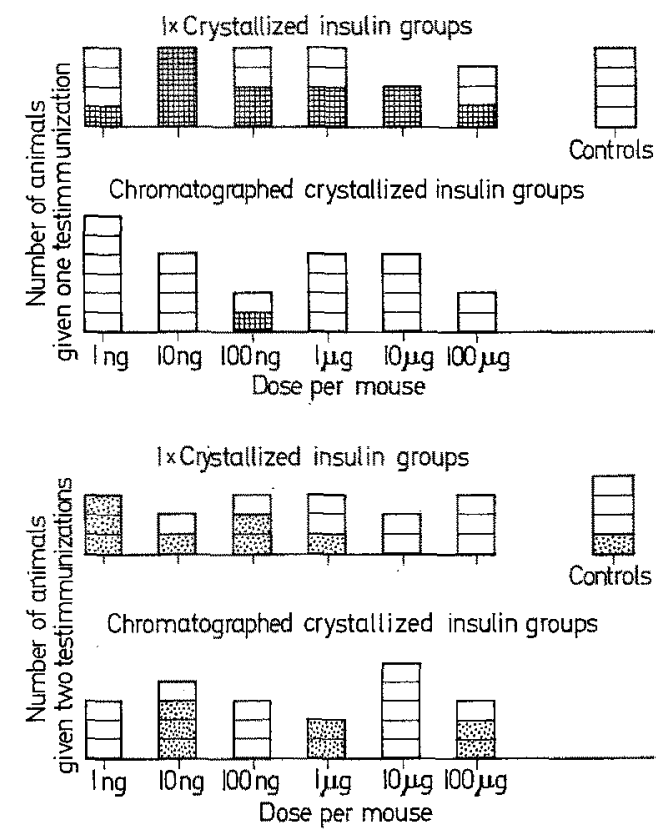

Periductulitis after one test immunization. Periductulitis after two test immunizations

and 3). A peri-insulitis was said to be present when the infiltrate consisted of more than 15 cells in serial sections. This finding was only partially associated with periductular or interacinar infiltrates. As a rule, only single islets of the pancreas (up to $10 \%$ ) were affected by inflammatory infiltration. Often, the in. filtrate was localised between an islet and an adjacent vessel. In some cases the infiltrate seemed to compress the islet (see Fig. 2) but, in general, there was no decomposition of the normal islet structure, nor were there degenerative changes of the beta cells. Cytologically, peri-insulitis was composed of lymphocytes and monocytic cells (immunoblasts?).

Periductulitis and peri-insulitis were distributed in the two main groups and their sub-groups as follows:

1. Once Crystallized Insulin Group:

Periductulitis, sometimes in association with focal interstitial pancreatitis (not shown in the table), was a frequent finding in this group with all dosages (Table 1). On the contrary, peri-insulitis was only found in a few animals that received once crystallized insulin at a dosage of 1 or $10 \mathrm{ng}$ (Table 2). The fre- 
quency of peri-insulitis and periductulitis did not depend on the number of test immunizations.

2. Chromatographed Insulin Group:

Periductulitis occurred, with one exception, only in animals which received a second test immunization (Table 1). This finding was not confined to a particular

Table 2. Distribution and frequeney of peri-insulitis in mice treated as described in "Table 1

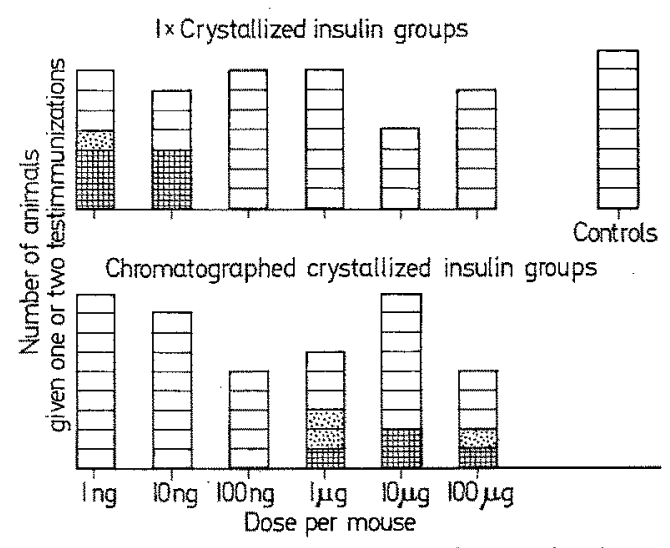

Peri-insulitis after one test immunization. Peri-insulitis after two test immunizations
Statistical methods were used to assess whether there was an adequate number of animals to warrant significant results. A comparison was made with the t-distribution of student.

Within the once crystallized insulin group $54 \%$ positive animals out of 13 , receiving low dosees were compared with $0 \%$ positive mice out of 24 , receiving high doses. The difference was statistically significant $(p<0.01)$. The same significance $(p<0.01)$ could be calculated for the results of $35 \%$ positive mice ont of 20 injected with high doses of chromatographed insulin, when compared with $0 \%$ of 22 mice of the low doses sub-groups.

The alterations of the islets (hyperplasia) and beta. cells (degranulation) in both groups and sub-groups showed no significant distribution; for this reason they are not discussed.

\section{Discussion}

Insulitis is a well documented phenomenon in the pathological anatomy of diabetes mellitus (Gepts, 1965). In animals insulitis can be induced by immunization with insulin (Renold et al., 1964; Toreson et al.

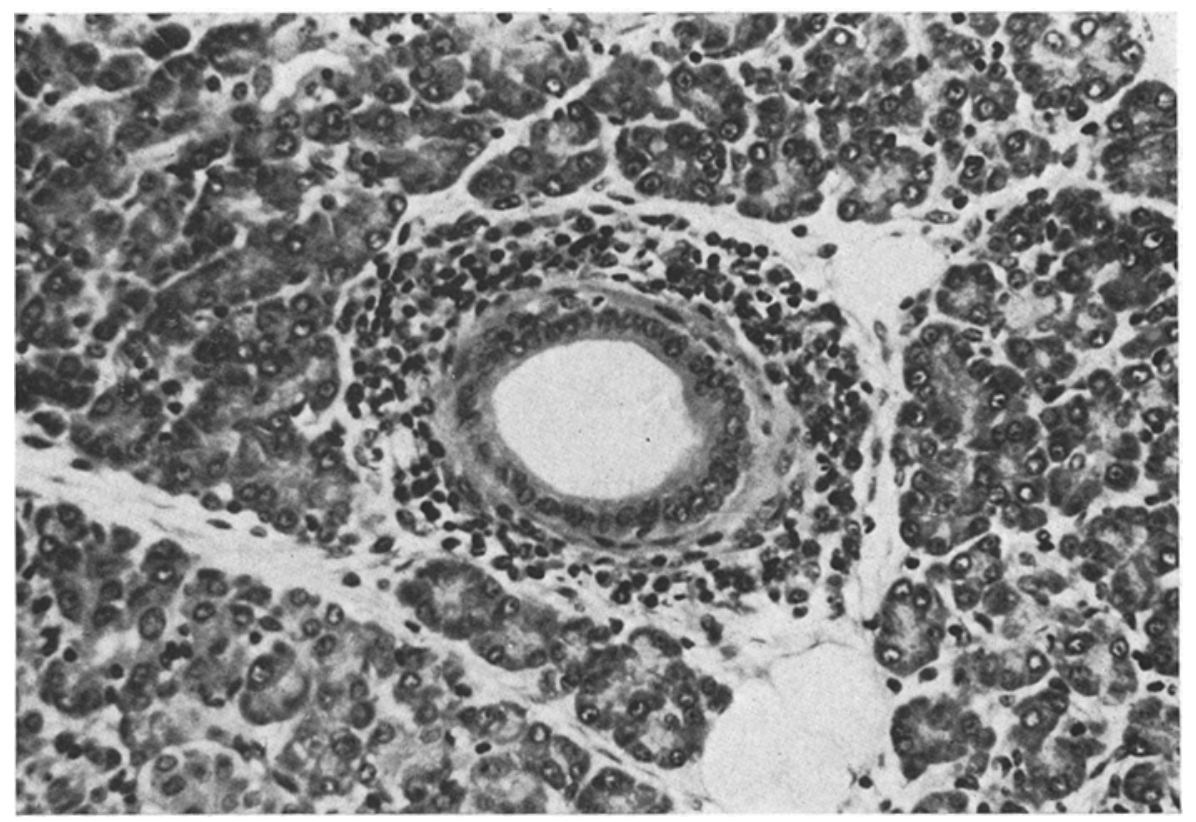

Fig. 1. Pancreas of mouse, repeatedly injected with once crystallized insulin without adjuvant. One test immunization (cryst. insulin plus adjuvant) was given before death to prove induction of tolerance. Marked periductulitis, No changes of the duct epithelium. PAS. $\times 300$

dosage. Interstitial pancreatitis was a rare finding but was also seen after the first test immunization (not shown in the table). The occurrence of peri-insulitis in the single sub-groups was related to a dosage of $1 \mu \mathrm{g}$ to $100 \mu \mathrm{g}$ (Table 2). A second test immunization had no influence on the frequency and dose-relation of peri-insulitis.
1964; Klöppel et al., 1972), by injection of anti-insulin serum (Lacy and Wright, 1965; Logothetopoulos and Bell, 1966; Freytag and Klöppel, 1969) and by infection with certain viruses (Craigehead and Steinke, 1971; Müntefering el al, 1971). So far the only animals developing insulitis after immunization with insulin are heifers, sheep and rabbits. Quite unexpectedly, we 
observed similar pancreatic changes in mice, which could be classed as peri-insulitis and peri-ductulitis. The mice had been immunized with once crystallized tolerance (Jansen, 1971a, b) to the single insulin preparations, the immunization procedures differ from the usual methods. Thus, prolonged pre-treatment with

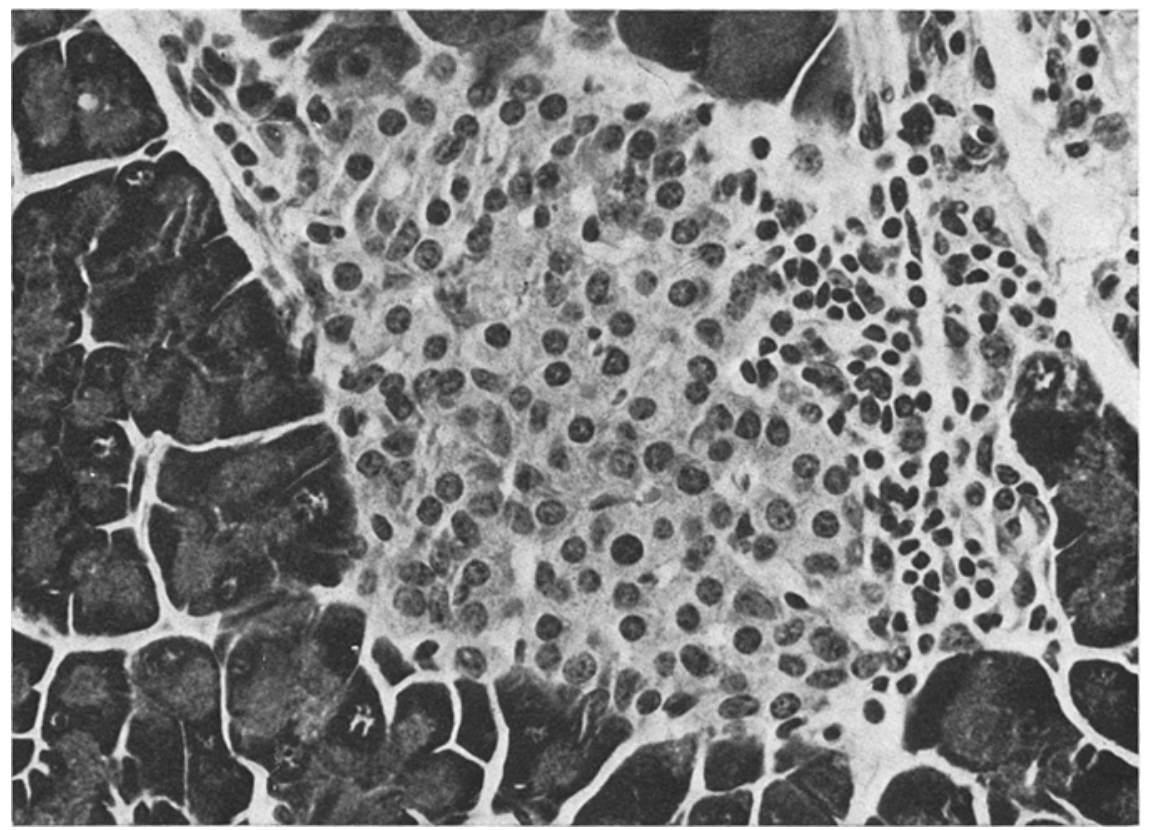

Fig. 2. Pancreas of mouse, repeatedly injected withonce crystallized insulin without adjuvant at a low dosage. One test immunization was given before death. Marked round-cell peri-insulitis compressing the islet. Left, a ductulus. PAS. $\times 500$

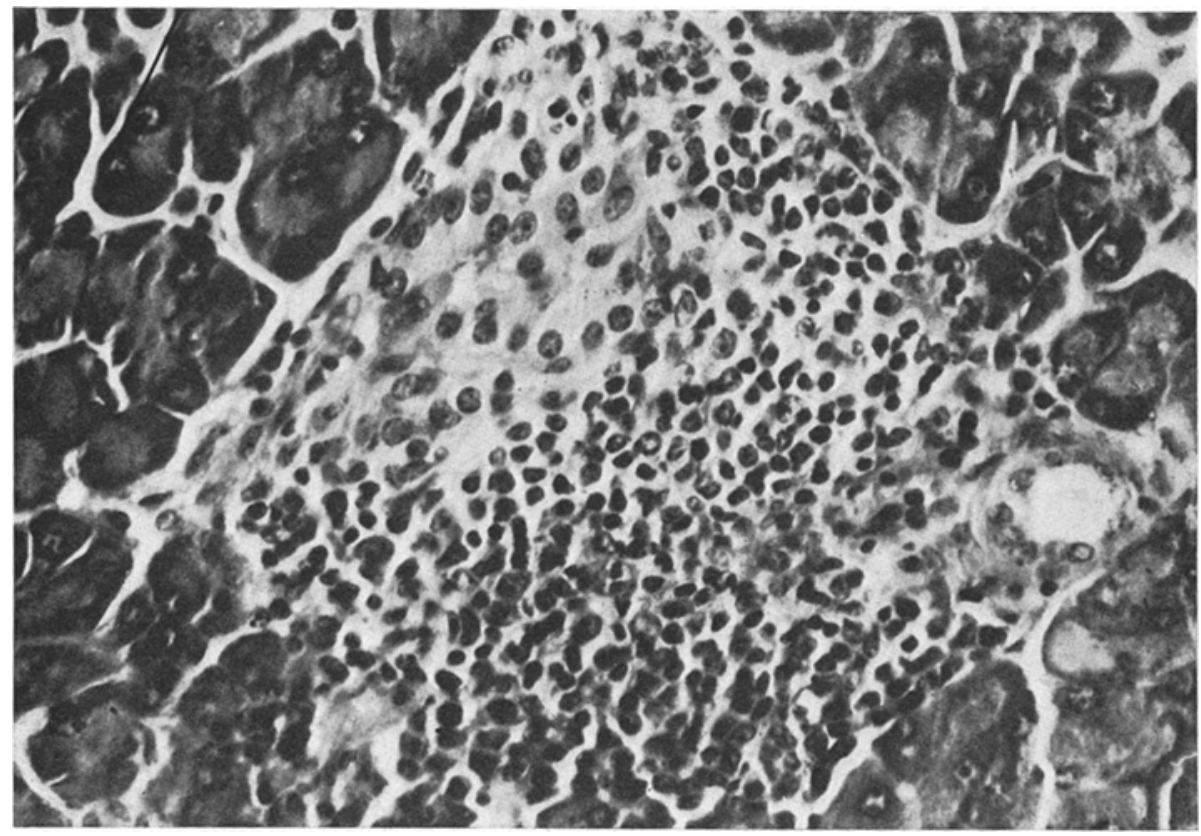

Fig. 3. Pancreas of mouse, repeatedly injected with! highly purified, chromatographed insulin without adjuvant at a high dosage. One test immunization was given before death. Note the slight but distinct peri-insular infiltration by lymphocytes and monocytic cells. No beta cell changes. PAS. $\times 500$

or highly purified, chromatographed insulin at various dosages in order to examine tolerance induction. Since these studies were designed primarily to investigate insulin preparations without added adjuvant was followed by a test immunization consisting of crystalline insulin in Freund's adjuvant. The test immuniza- 
tion was given to demonstrate the induction of tolerance: Normal and tolerant animals could not be distinguished before the test immunization, since neither produce antibodies. After the test immunization, stimulated and normal animals, in. cluding the positive controls, developed antibodies, while tolerant animals did not. Because of its high antigenicity, crystalline insulin was used for the test immunization. As all animals received the test immunization with impure crystallized insulin, pancreatic infiltrates representing a cellular reaction to insulin or associated proteins was to be expected in all animals, including the controls. However, no periinsular or insular infiltrates were observed in the controls. Furthermore, except in one animal, periductulitis was absent. It is concluded that only the pre-treatment with the insulin preparations and not the test immunization, accounted for peri-insulitis and periduotulitis in this experiment.

Peri-insulitis in mice shows a somewhat different pattern to that in rabbits and cattle. It is predominantly found in the peri-insular area. It does not encroach along the sinusoids upon the islets. Furthermore, only single islets are involved by the infiltration. On the other hand, the cytological character of the infiltrates in cattle and rabbits seems to be similar to those seen in mice. Periductulitis can also be observed in all three species. Because of this, the question remains unanswered as to whether or not the periinsular infiltrates in mice were truly immune insulitis, or only represented a non-specific alteration, possibly caused by the repeated intra-peritoneal injections. The good correlation, however, between the occurrence of the panoreatic infiltrates and the pre-treatment with once crystallized or chromatographed insulin suggests an immunological specificity of peri-insulitis and periductulitis. The fact that insulitis und periductulitis in rabbits was only observed when insulin or insulinlike contaminants plus adjuvant were injected, while Freund's adjuvant by itself did not induce any alterations (Klöppel, Altenähr, Jansen and Freytag, in preparation) supports this assumption.

Since peri-insulitis in mice was found after injecting chromatographed or once crystallized insulin, a common antigen is thought responsible. The antigen may be the unaltered or altered insulin or an associated protein. If the antigen was insulin, one would anticipate that peri-insulitis would occur with the same dose of both insulin preparations or even at higher doses of once crystallized insulin. Once crystallized insulin contains only $80 \%$ true Sanger insulin (Schlichtkrull, 1969), whereas chromatographed insulin consists of about $100 \%$ monomer insulin. However, the results do not confirm this hypothesis because peri-insulitis is observed at a much higher dosage of chromatographed insulin than once crystallized insulin. This fact may therefore indicate that the crystalline insulin preparations contain an antigen, specifically inducing insulitis, which differs from true Sanger insulin and is only present in minimal amounts in the chromatographed insulin preparation. However, existence of such antigen remains purely hypothetical since it could not be demonstrated.

Furthermore it is of interest that in all groups given only one test immunization, the occurrence of periductulitis was almost completely confined to those animals that received once crystallized insulin prior to the test immunization. The significance and specificity of this finding is unclear, but it may point to a second antigen within the fractions of crystallized insulin, possibly of extrainsular origin.

\section{References}

Craighead, J.E., Steinke, J.: Diabetos mellitus-like syndrome in mice infected with encephalomyocarditis virus. Amer. J. Path. 63, 119 (1971).

Freytag, G., Klöppel, G.: Experimentelle Insulitis und Pankreatitis nach Immunseren gegen Pankreasextrakte verschiedener Reinheitsgrade. Beitr. path. Anat. 39, $138(1969)$.

Gepts, W.: Pathologic anatomy of the pancreas in juvenile diabetes mellitus. Diabetes 14, 619 (1965).

Jansen, F.K.: Tolerance to high and low doses of natural crystalline insulin. Diabetologia 7, 290-292 (1971 a).

Jansen, F.K. : The ability of MC-insulin or $1 \times$ crystallized insulin in the development of immunologieal tolerance in mice. Diabetologia 7, 485 (1971b) Abstr.

Klöppel, G., Altenähr, E., Freytag, G.: Studies on ultrastructure and immunology of the insulitis in rabbits immunized with insulin. Virchows Arch. Abt. A. Path. Anat. 356, 1-15 (1972).

Lacy, P.E., Wright, P.H. : Allergic intestitial pancreatitis in rats injected with guinea pig anti-insulin serum. Diabetes 14, 634 (1965).

LeCompte, P.M.: "Insulitis" in early juvenile diabetes. Arch. Path. 66, 450 (1958).

LeCompte, P.M., Steinke, J., Soeldner, J.S., Renold, A.E.: Changes in the islets of Langerhans in cows injected with heterologous and homologous insulin. Diabetes 15, 586 (1966).

LeCompte, P.M., Legg, M.A.: Insulitis (lymphocytic infiltration of pancreatic islets) in late-onset diabetes. Diabetes 21, 762-769 (1972).

Lee, J.C., Grodsky, G.M., Caplan, C.J., Craw, L.: Experimental immune diabetes in the rabbit. Amer. J. Path. 57, 597 (1969).

Logothetopoulos, J., Bell, E.G.: Histological and autoradiographic studies of the islets of mice injected with insulin antibody. Diabetes 15, 205 (1966).

von Meyenburg, H.: Uber "Insulitis" bei Diabetes. Schweiz. med. Wschr. 70, $247(1940)$.

Müntefering, H., Schmidt, W.A.K., Körber, W.: Zur Virusgenese des Diabetes mellitus bei der weißen Maus. Dtsch. med. Wschr. 96, 693 (1971).

Renold, A.E., Soeldner, J.S., Steinke, J.: Immunological studies with homologous and heterologous pancreatic insulin in the cow. Ciba Foundation Colloquia Endocrinol. 15, 122 (1964).

Renold, A.E., Gonet, A.E., Vecchio, D.: Immunopathology of the endocrine pancreas. In: Textbook of Immunopathology, ed. by P.A. Miescher and H.J. Müllereberhard. Vol. II, p. 595. New York and London: Grune and Stratton 1969. 
Schlichtkrull, J., Brange, J., Ege, H., Hallund, O. Heding, L.G., Christiansen, A.H., Jorgensen, K., Markussen, J., Stahnke, P., Sundby, F., Volund, A.: Proinsulin and related proteins. European Association for the Study of Diabetes. 5th annual meeting, Montpellier 1969 .

Steiner, H.: Insulitis beim perakuten Diabetes des Kindes. Klin. Wschr. 46, $417(1968)$

Steiner, D.F., Hallund, O., Rubenstein, A., Cho, S., Bayliss, C.: Isolation and proterties of proinsulin, intermediate froms and other minor components from crystalline bovine insulin. Diabetes 17, 725 (1968).
Toreson, W.E., Feldman, R., Lee, J.C., Grodsky, G.M.: Pathology of diabetes mellitus produced in rabbits by means of immunization with beef insulin. Amer. J. clin. Path. 42, 531 (1964).

Weber, E.: Grundriß der biologischen Statistik, 6. Aufl. Jena: Gustav Fischer Verlag 1967.

Priv.-Doz. Dr. G. Freytag

Pathologisches Institut

der Universität

D-2000 Hamburg

Federal Republic of Germany 